\title{
Influence of particle size on the ice nucleating ability of mineral dusts
}

\author{
A. Welti, F. Lüönd, O. Stetzer, and U. Lohmann \\ ETH Zurich, Institute for Atmospheric and Climate Science, Switzerland \\ Received: 6 February 2009 - Published in Atmos. Chem. Phys. Discuss.: 16 March 2009 \\ Revised: 13 July 2009 - Accepted: 30 August 2009 - Published: 16 September 2009
}

\begin{abstract}
The recently developed Zurich Ice Nucleation Chamber (ZINC) was used to explore ice nucleation of size-selected mineral dust particles at temperatures between $-20^{\circ} \mathrm{C}$ and $-55^{\circ} \mathrm{C}$. Four different mineral dust species have been tested: montmorillonite, kaolinite, illite and Arizona test dust (ATD). The selected particle diameters are $100 \mathrm{~nm}$, $200 \mathrm{~nm}, 400 \mathrm{~nm}$ and $800 \mathrm{~nm}$. Relative humidities with respect to ice $\left(\mathrm{RH}_{i}\right)$ required to activate $1 \%$ of the dust particles as ice nuclei (IN) are reported as a function of temperature. An explicit size dependence of the ice formation efficiency has been observed for all dust types. $800 \mathrm{~nm}$ particles required the lowest $\mathrm{RH}_{i}$ to activate. Deposition nucleation below water saturation was found only below $-30^{\circ} \mathrm{C}$ or $-35^{\circ} \mathrm{C}$ dependent on particle size. Minimum $\mathrm{RH}_{i}$ for $1 \%$ activation were $105 \%$ for illite, kaolinite and montmorillonite at $-40^{\circ} \mathrm{C}$, respectively $110 \%$ for ATD at $-45^{\circ} \mathrm{C}$. In addition, a possible parameterisation for the measured activation spectra is proposed, which could be used in modeling studies.
\end{abstract}

\section{Introduction}

Mineral dust particles play an important role as IN in the hydrological cycle and the radiation balance of the atmosphere (Szyrmer and Zawadzki, 1997). More than 50\% of the midlatitude precipitation and $30 \%$ of the tropical rainfall forms via the ice phase (Heymsfield, 2005; Lau and Wu, 2003). From the analysis of the composition of aerosol particles found in the center of ice crystals, it is known that mineral dusts are commonly involved in atmospheric ice formation (Wallace and Hobbs, 2006; DeMott et al., 2003a).

Mineral dust is an important component of natural aerosols in the atmosphere. The major sources are sparsely vege-

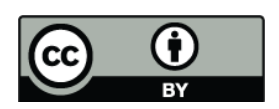

Correspondence to: A. Welti (andre.welti@env.ethz.ch) tated areas, deserts and semi-arid regions from where dust is emitted and distributed on a global scale (Prospero, 1999). Even at the South Pole, some particles found in snowflakes are composed of mineral dusts (Rogers and Yau, 1989). Anthropogenic changes of land use, such as over grazing and cultivation, lead to growth of arid areas and thus to greater mineral dust concentrations in the atmosphere (DeMott et al., 2003b). Tegen et al. (2004) estimated the anthropogenic contribution to the total dust load in the atmosphere to be 5\%-7\%. Li et al. (1996) designate the dust mobilized by human activity an anthropogenic pollutant. Increased dust loads in the atmosphere foster the formation of ice crystals and thereby influence both the extent of cloud cover and the lifetime of clouds (Wallace and Hobbs, 2006). As a consequence, this may lead to changes in global precipitation patterns.

The presence of ice crystals also modifies the radiative properties of clouds. Of great interest are cirrus clouds encountered in the upper troposphere in a temperature range between $-20^{\circ} \mathrm{C}$ and $-80^{\circ} \mathrm{C}$, which make up approximately one third of the total cloud cover (Warren and Eastman, 2007). These clouds affect the cloud radiative forcing by reflecting incoming shortwave radiation from the sun and by absorbing outgoing infrared radiation from the earth's surface. Depending on their optical thickness, the net effect on climate can either be cooling or warming (Zhang et al., 1999). The radiative properties of cirrus clouds depend on the temperature and humidity of the environment in which the clouds form, as well as on the ice nucleation characteristics of the aerosols involved. In turn, the ability of a specific aerosol to trigger ice nucleation depends on the atmospheric conditions.

Ice crystals form in the atmosphere via homogeneous nucleation of solution droplets or via heterogeneous nucleation on solid IN. Heterogeneous ice nucleation sets in at distinctly lower ice saturation or supercooling than homogeneous freezing (Pruppacher and Klett, 1997). Four different mechanisms of heterogeneous ice nucleation have been

Published by Copernicus Publications on behalf of the European Geosciences Union. 
recognized (Vali, 1999; Rogers and Yau, 1989). Ice is either formed by direct deposition of water vapour on ice nuclei without forming an intermediate liquid phase, by immersion freezing, in which IN immersed in a droplet initiate freezing, by condensation of water vapour on an ice nucleus followed by freezing (condensation freezing), or by freezing of supercooled drops that come in contact with IN (contact freezing).

Earlier measurements, for example by Roberts and Hallett (1968) or by Rogers and Yau (1989) showed various ice nucleation efficiency of mineral dusts in the deposition mode. For an overview of studies with montmorillonite, kaolinite, illite and ATD we refer to the work of Eastwood et al. (2008), Knopf and Koop (2006) and Zimmermann et al. (2008). Archuleta et al. (2005) investigated the size dependence of deposition nucleation of Asian Dust. They concluded that there is a clear size effect on heterogeneous ice formation in the way that smaller particles require higher ice saturation to activate. Kanji et al. (2008) analyzed the dependence of the particle surface area on the onset of ice formation on mineral dust particles at $-40^{\circ} \mathrm{C}$. They report a higher probability of ice nucleation i.e. decreasing $\mathrm{RH}_{i}$ necessary to start ice formation with increasing surface area.

In this paper we focus on the impact of mineral dust species and particle size on ice nucleation in the deposition mode below water saturation under conditions relevant to the atmosphere. Dependent on atmospheric dynamics and the distance to the dust emission source, the size distribution of dust transported to a certain location, varies in terms of the median particle diameter. Therefore the particle size dependency of ice nucleation is an important factor for modeling studies which consider heterogeneous ice formation. The difference between the dust species is of interest because natural sources have strongly varying dust compositions. Measurements of the ice nucleation capacity of different dust species under similar conditions can give evidence which particle properties are important for the ice nucleation ability of a dust type. This may help to improve the theoretical treatment of atmospheric ice formation depending on the properties of the involved aerosol.

We present experimental data of the conditions necessary to activate $1 \%$ of the selected mineral dust aerosol as ice nuclei together with the effort to extract the particle properties that are important for the freezing process. The temperature range where deposition nucleation on the tested mineral dusts is a relevant process is discussed. In addition we propose a size and mineral dust species dependent parametrisation for deposition nucleation which could be implemented in a numerical model of cloud microphysics.

\section{Dust samples}

Mineral dusts originating from deserts and semi-arid regions are mainly silicate particles. Four different dust samples were used in this study: montmorillonite (K-10, Aldrich), kaolinite (Fluka), illite (NX Nanopowder, Arginotec) and ATD (Powder Technology Inc.). These dust samples were used untreated for the experiments and the aerosols were generated via dry dispersion. Montmorillonite, kaolinite and illite are known to be three main components of natural mineral dust and are frequently found in silicate aerosols (Claquin et al., 1999). Their ability to efficiently nucleate ice in the deposition mode has been shown in previous studies (Salam et al., 2006; Roberts and Hallett, 1968). ATD was examined to provide data for later comparison with other laboratory experiments. ATD is composed of various mineral species and can be thought of as a model dust that originates from deserts. It has also been proven to be an efficient IN in the deposition mode (Knopf and Koop, 2006; Möhler et al., 2005). The size distribution of the dust samples were measured with a scanning mobility particle sizer (SMPS, TSI Model 3936) to ensure that particles in the investigated size range $(100-800 \mathrm{~nm})$ are present in sufficient amounts. The morphology of representative particles of every dust sample was studied with a scanning electron microscope (SEM, LEO 1530 Gemini). Powder suspensions were immersed on carbon tapes and subsequently sputter coated by a thin Gold layer. High resolution secondary electron (in-lens SE detector) images were acquired at $3 \mathrm{kV}$. Particles were randomly selected for imaging with some emphasis on the smallest available aggregates. As can be seen in the SEM pictures (Fig. 1) the used mineral dust particles are of highly irregular shape. The surface of kaolinite is relatively smooth, whereas montmorillonite, illite and ATD have rougher surfaces.

\section{Experimental setup}

A schematic picture of the experimental setup is shown in Fig. 2. Mineral dust aerosol particles are generated in a Fluidized Bed Aerosol Generator (TSI Model 3400A) and transported in non-stick conductive elastic tubes to a differential mobility analyzer (DMA, TSI Model 3081) while first passing through a neutralizer. The neutralizer contains a Po210 radioactive source, which reduces the particle electrical charge to the Boltzmann equilibrium level (Kim et al., 2005). In the DMA, particles with a specified electrostatic mobility diameter $(100 \mathrm{~nm}, 200 \mathrm{~nm}, 400 \mathrm{~nm}$ and $800 \mathrm{~nm})$ were selected. Particles selected with the DMA carry positive charges. To avoid charge effects, the sample flow passes through a second neutralizer to obtain a neutral charge distribution. Control measurements without the second neutralizer were performed to check if the positive charges remaining on the dust particles influence the conditions under which particles nucleate ice in the deposition mode. The measurements without a neutralizer behind the DMA, however, showed no recognizable deviation in nucleation behavior. This observation seems to confirm the finding of Winkler et al. (2008) that the nucleation of particles with a diameter above $4 \mathrm{~nm}$ is independent of the charging state. Due to multiple charges, 
larger particles with the same mobility are likely to be present in a size selected sample. Their contribution to the total amount of particles is large in the $100 \mathrm{~nm}$ and $200 \mathrm{~nm}$ size range, because these sizes are located in the upslope part of the sample size distribution and larger, multiple charged particles with the potential to have the same mobility are present in high amounts. For example, doubly charged $149 \mathrm{~nm}$ and triply charged $191 \mathrm{~nm}$ particles exhibit the same electrostatic mobility as $100 \mathrm{~nm}$ particles, and $318 \mathrm{~nm}$ and $427 \mathrm{~nm}$ that of $200 \mathrm{~nm}$ particles. Results obtained with these sizes are only qualitative and can not be used for a quantitative analysis. The multiple charged particles that contribute to the $400 \mathrm{~nm}$ and $800 \mathrm{~nm}$ size range are in the down slope of the size distribution. Therefore these multiple charged particles are negligible, because they are much less abundant than the single charged. An example size distribution illustrating the multiple charge issue is shown in Fig. 3.

After the DMA, the size selected sample flow is split into two equal flows. One half is used to measure the total aerosol particle concentration in the sample air with a butanol-condensation particle counter (CPC, TSI Model 3010). The other half of the sample flow is passed to the Zurich Ice Nucleation Chamber (ZINC, cf. next chapter) where a fraction of the dust particles nucleates ice crystals. The ice crystals and unactivated dust particles exiting ZINC are counted and classified into size equivalent bins with an optical particle counter (OPC, CLiMET Cl-3100).

\section{Ice nucleation experiment}

The experiments were carried out with the recently developed parallel plate continuous flow diffusion chamber ZINC. ZINC consists of two sections: the nucleation section where high $\mathrm{RH}_{i}$ can be generated, and the evaporation section. The evaporation section is held at ice saturation, so water droplets that might condense in the nucleation section when experimenting at relative humidities above water saturation, evaporate before reaching the OPC. The design and functional details of ZINC are described by Stetzer et al. (2008).

The ice nucleation experiments are started at ice saturation inside the chamber. Ice saturation is achieved by coating the inside walls of the chamber with ice prior to the measurements. Applying different temperatures to the ZINC walls leads to an ice supersaturation profile with a maximum roughly in the center of the chamber. The supersaturation establishes because the saturation vapour pressure curve depends non-linearly on temperature. An increase in $\mathrm{RH}_{i}$, while keeping the sample temperature constant, can be obtained by simultaneously ramping up the temperature of one wall while the other wall is cooled down at the same rate. The temperature step by which the wall temperatures are simultaneously increased and decreased is one Kelvin.

The total air flow through the chamber is 10 liters per minute and divides into $1 \mathrm{lpm}$ of sample air carrying the

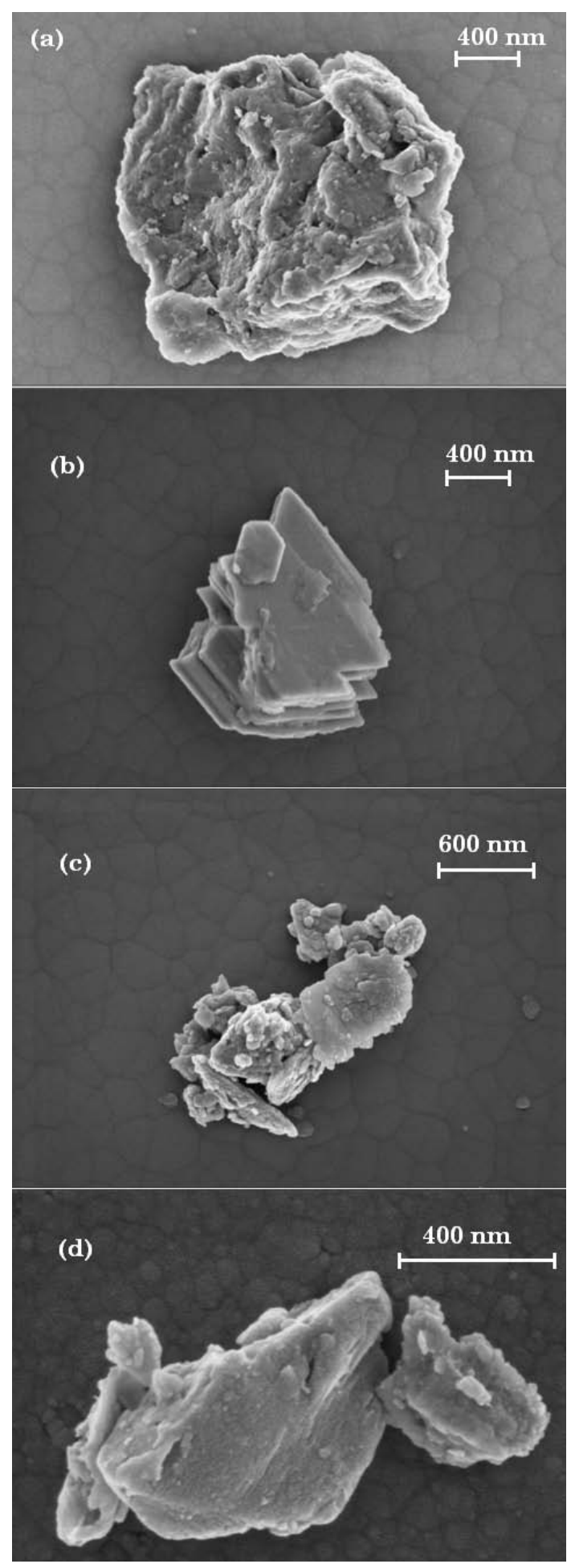

Fig. 1. Representative SEM images of individual particles of (a) montmorillonite, (b) kaolinite, (c) illite and (d) ATD. 


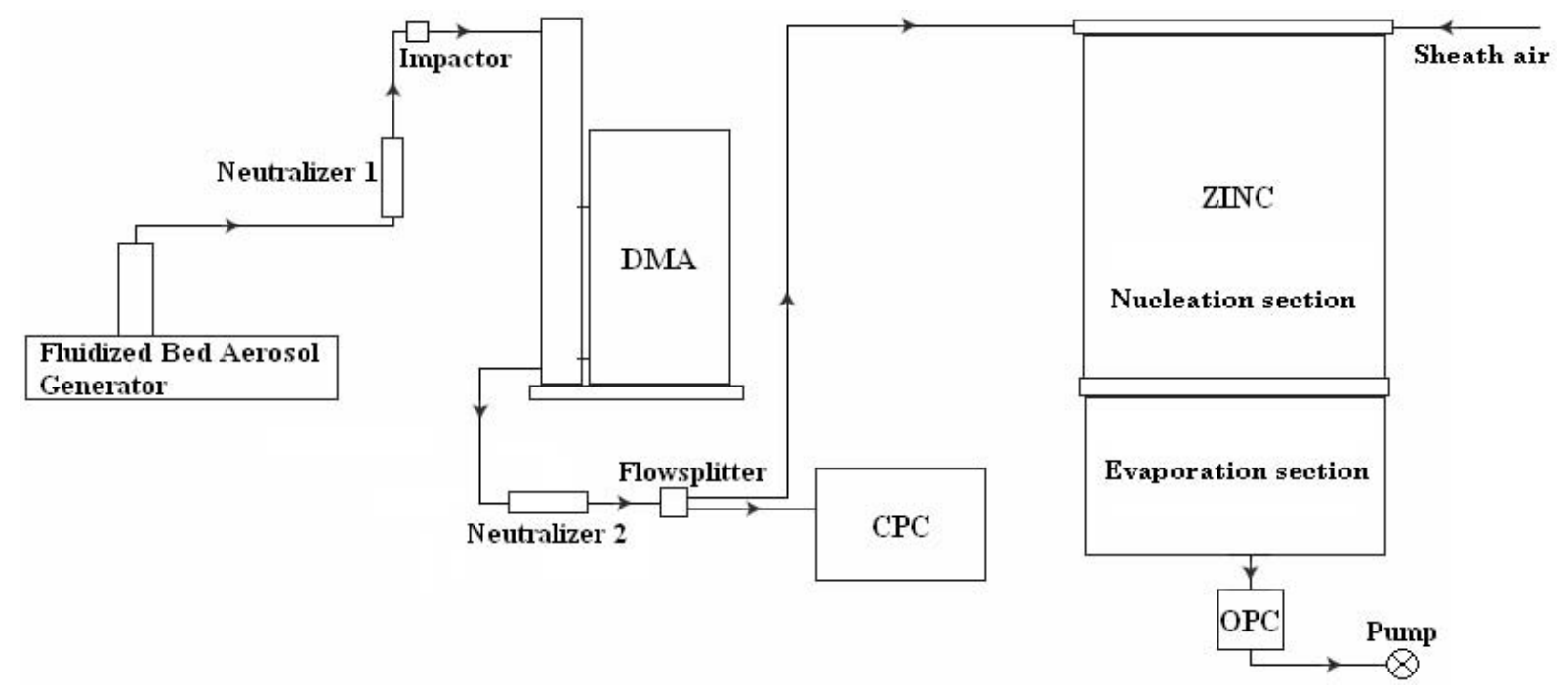

Fig. 2. Experimental setup. The arrows indicate the direction of the sample flow through the system. A fluidized bed aerosol generator is used to produce mineral dust aerosols. The aerosols are forwarded into the DMA where a specific mobility is selected. One half of the sample flow is used to measure the particle concentration with the CPC and the other half is passed into ZINC where ice nucleation takes place. The ice crystals exiting the ZINC are detected by the OPC.

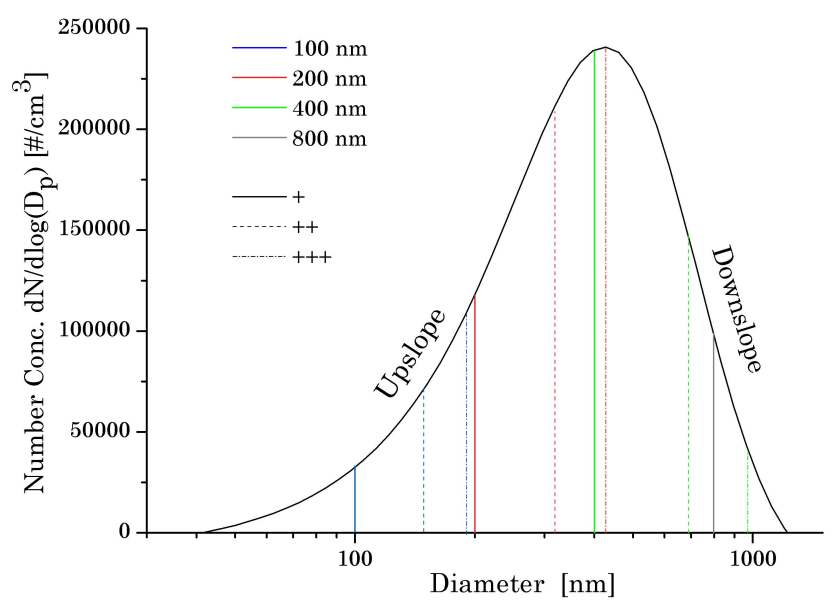

Fig. 3. Example size distribution. Used particle sizes of equal mobility due to multiple charges are shown in one color. The line style indicates the charging state. A single plus denotes single charge, and double (triple) plus stand for double (triple) charges.

monodisperse mineral dust particles and $91 \mathrm{pm}$ of filtered sheath air. With these settings, the sample aerosol has a residence time of $12 \mathrm{~s}$ in the main chamber and another $8 \mathrm{~s}$ in the evaporation section (Stetzer et al., 2008). The sample flow can be considered laminar.

The four different mineral dust species were investigated at eight temperatures between $-20^{\circ} \mathrm{C}$ and $-55^{\circ} \mathrm{C}$ in $5^{\circ} \mathrm{C}$ intervals. During the experiments, wall temperature differ- ences ranged from $0^{\circ} \mathrm{C}$ to $24^{\circ} \mathrm{C}$, leading to ice supersaturations of $0 \%$ to $90 \%$. Due to the temperature difference between the warm and the cold wall, there is a buoyant updraft which slightly shifts the sample flow towards the cold wall. This small dislocation of the flow profile has been taken into account for the determination of the temperature and saturation condition of the sample flow. Typical aerosol number concentrations were 1000 particles per $\mathrm{cm}^{3}$. Figure 4 shows an example of an experimental run. In the supersaturated region within ZINC, a fraction of the ice nuclei becomes activated and forms ice crystals. The size of the ice crystals is in the range of a few micrometers where they can be reliably counted by the OPC at the outlet of the chamber.

The activated fraction of particles (Eq. 1) was calculated as the ratio of the number concentration of ice crystals detected by the OPC to the total number concentration of particles measured with the CPC as described in Sect. 3.

Activated Fraction $=\frac{\text { \# Ice Crystals }}{\text { \# Aerosol Particles }}$

Data points for the activated fraction were obtained at a time resolution of $5 \mathrm{~s}$ during the increase of supersaturation. The experiment was carried out under the same conditions with each of the four mineral dust species.

\section{Results}

Measurements of the $1 \%$ activated fraction threshold $\mathrm{RH}_{i}$ as a function of temperature for four mineral dust samples of selected particle diameters of 100, 200, 400 and $800 \mathrm{~nm}$ 


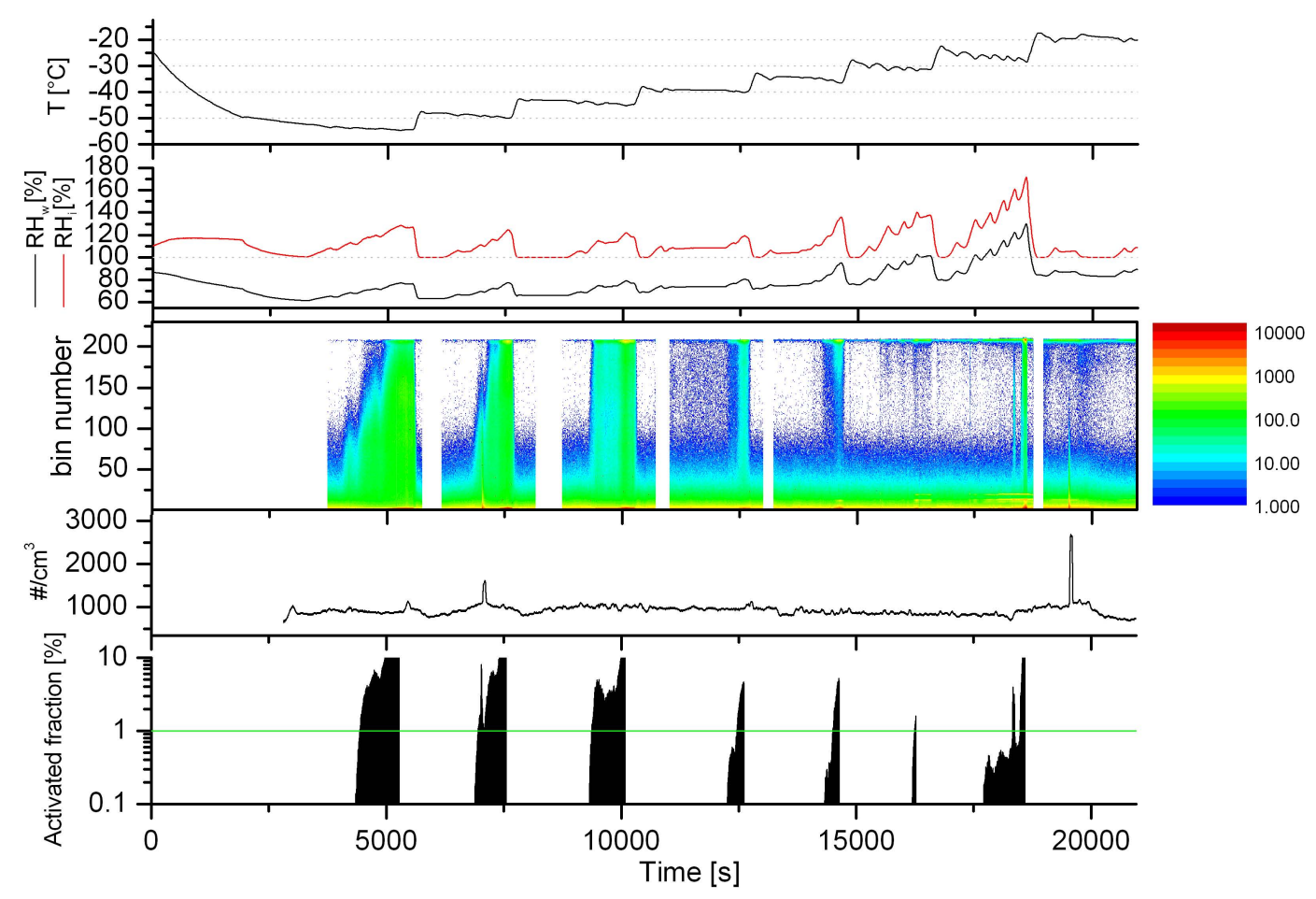

Fig. 4. Time evolution of ice nucleation measurements with $200 \mathrm{~nm}$ kaolinite particles. The two top panels show the temperature and humidity evolution at the sample location. The middle panel displays the color coded particle size spectra obtained from the OPC and beneath, the particle count history of the CPC is shown. At the bottom the calculated activated fraction is plotted.

are shown in Fig. 5. The data for $1 \%$ activated fraction show a distinct effect of the particle size on deposition nucleation. Smaller particles require a higher $\mathrm{RH}_{i}$ to be activated. This finding seems to agree with nucleation theory and has already been confirmed under different experimental conditions in previous studies e.g. by Archuleta et al. (2005) or Berezinski et al. (1988). For every dust sample there is a maximum nucleation efficiency at a specific temperature, i.e. a minimum supersaturation threshold for $1 \%$ activated fraction. The lowest $\mathrm{RH}_{i}$ required to reach $1 \%$ activation is found to be at lower temperatures for smaller particles than for larger particles. Depending on the dust species, the corresponding temperature shifts from approximately $-50^{\circ} \mathrm{C}$ for $100 \mathrm{~nm}$ particles to $-35^{\circ} \mathrm{C}$ for $800 \mathrm{~nm}$ particles. The minimum $\mathrm{RH}_{i}$ required for the onset of deposition nucleation on $800 \mathrm{~nm}$ particles has been observed to be around $105 \%$ for montmorillonite, kaolinite and illite. A slightly higher threshold of $110 \% \mathrm{RH}_{i}$ is needed for ATD particles to act as deposition nuclei. For smaller particles and at temperatures outside this range, a higher $\mathrm{RH}_{i}$ is needed to start ice nucleation. At temperatures higher than $-30^{\circ} \mathrm{C}$, relative humidities above water saturation were required before ice formation was detected. The observed increase in the required $\mathrm{RH}_{i}$ to nucleate ice on $1 \%$ of the dust particles at temperatures below $-45^{\circ} \mathrm{C}$ is probably caused by diffusion limited particle growth. At higher temperatures the activated particles grow to a size larger than $1 \mu \mathrm{m}$ where they can be clearly distinguished from inactivated dust particles. Below $-45^{\circ} \mathrm{C}$, a part of the particles that are activated might not be able to grow to a size large enough to be distinguished from the unactivated particle fraction by the OPC measurement. Therefore the measured ice fraction at low $\mathrm{RH}_{i}$ tends to underestimate the effective activated fraction.

Activation spectra were used to compare the nucleation behaviour for the whole range of $\mathrm{RH}_{i}$ s set during the measurements. Activation spectra of illite and kaolinite in the temperature range from $-30^{\circ} \mathrm{C}$ to $-40^{\circ} \mathrm{C}$ are shown in Fig. 6. Similar results are obtained for all measured temperatures and for montmorillonite and ATD (cf. supplement http://www.atmos-chem-phys.net/9/ 6705/2009/acp-9-6705-2009-supplement.pdf). As can be seen in Fig. 6, the transition from activation above water saturation to activation below water saturation shifts to higher temperatures for larger particles. At $-30^{\circ} \mathrm{C}$, particles with $400 \mathrm{~nm}$ and $800 \mathrm{~nm}$ in diameter were able to nucleate ice below water saturation, whereas $100 \mathrm{~nm}$ and $200 \mathrm{~nm}$ particles started to nucleate ice below water saturation only at $-35^{\circ} \mathrm{C}$. For some of the illite and kaolinite samples a discontinuous increase in the activated fraction at $-35^{\circ} \mathrm{C}$ has been observed as water saturation was reached (see Fig. 6). This is 

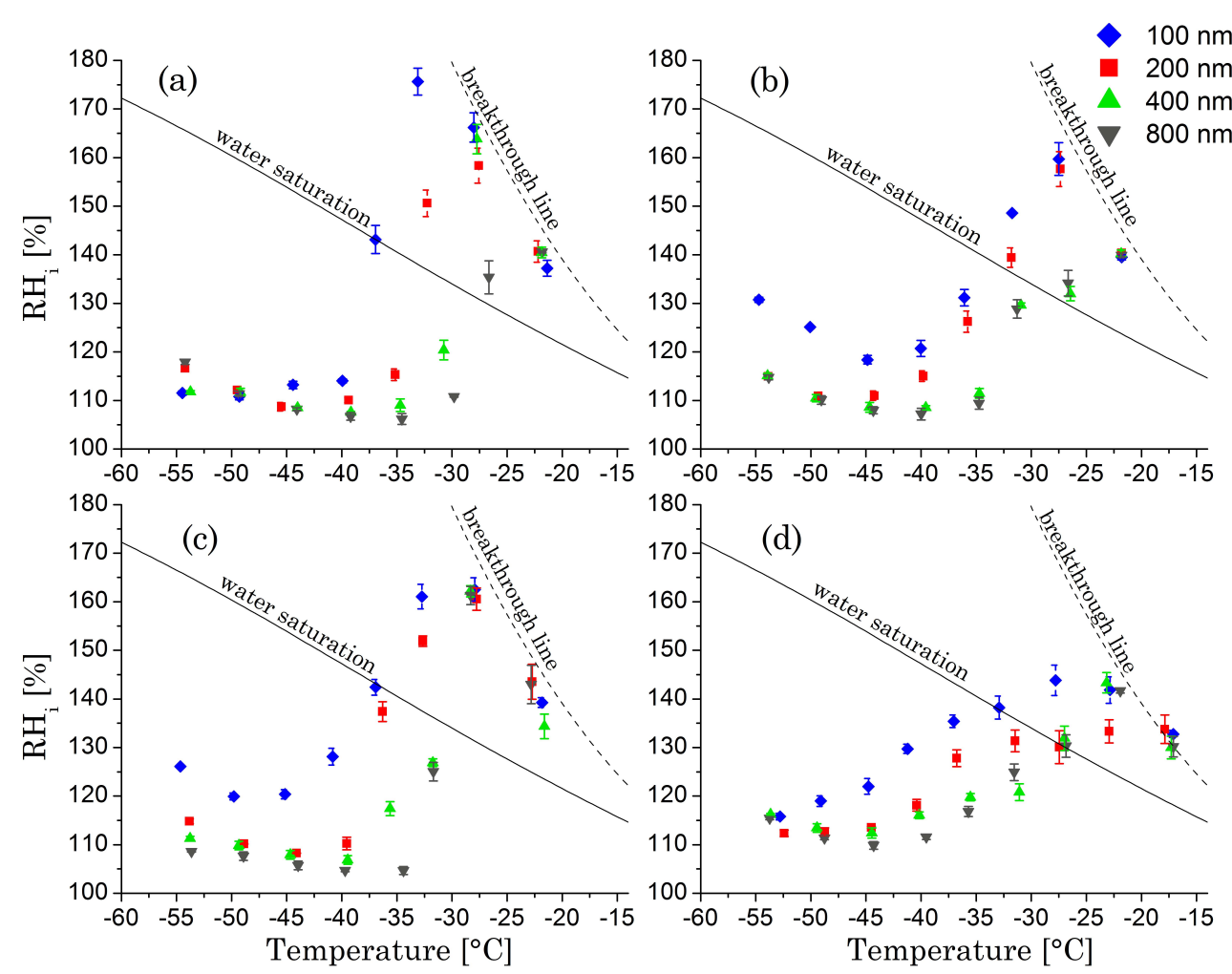

Fig. 5. $\mathrm{RH}_{i}$ required for $1 \%$ activated fraction as a function of temperature of (a) montmorillonite, (b) kaolinite, (c) illite, (d) ATD for different particle sizes. The water saturation line is shown as a solid, black line. The breakthrough line marks the region where water drops condensed in the nucleation section, grow large enough to pass the evaporation section and thus are also detected by the OPC. Error bars represent the maxima and minima $\mathrm{RH}_{i}$ measured during a period of $\pm 20 \mathrm{~s}$ around the detection of $1 \%$ activated fraction.

most likely due to the onset of condensation freezing in addition to deposition nucleation. Additional measurements are needed to clarify the transition from deposition nucleation to the condensation mode, as evidence in the presented data is only seen in a few instances.

For future use of the presented data in numerical studies, a parameterisation scheme for the activated fraction as a function of supersaturation with respect to ice $\left(S_{i}\right)$ has been developed. For this analysis, only activations below water saturation were used because with the present experiment, condensation and deposition mechanisms cannot be unambiguously distinguished above water saturation. The exponential fit proposed by Möhler et al. (2006) for deposition nucleation was tested for the measured data, but it matched poorly. As the activated fraction is expected to saturate at high $\mathrm{RH}_{i}$, curve functions which exhibit saturation behavior have been tested. The best fit to the data was obtained with a sigmoidal shaped fit curve (Eq. 2) which has its point of inflection at $50 \%$ activated fraction and saturates at $100 \%$.

Activated Fraction $=\frac{1}{1+\alpha \cdot \exp \left[-\beta \cdot\left(S_{i}-S_{0}\right)\right]}$

An example of this sigmoidal fit to the measured activation spectra for $400 \mathrm{~nm}$ kaolinite particles at $-55^{\circ} \mathrm{C}$ is shown in Fig. 7. $\alpha$ and $\beta$ are non-dimensional, temperature dependent empirical constants, $S_{0}$ is the threshold ice saturation for $1 \%$ activated fraction determined experimentally and $S_{i}$ is the supersaturation with respect to ice. A selection of fit parameters is given in Table 1 for $200 \mathrm{~nm}, 400 \mathrm{~nm}$ and $800 \mathrm{~nm}$ particles of montmorillonite and kaolinite.

\section{Discussion}

The measurements demonstrate that deposition nucleation is an efficient ice formation mode under conditions well below water saturation. In cirrus formation deposition nucleation might inhibit homogeneous ice nucleation by depleting the available water vapour content. In addition air needs to reach colder temperatures before water saturation can be achieved. Therefore, deposition nucleation changes the prevailing conditions for subsequent processes like homogeneous freezing.

A clear size dependence for the ice activated fraction of deposition nuclei at a given temperature and ice saturation is found for montmorillonite, kaolinite, illite and ATD dust particles. Larger particles tend to induce ice nucleation at lower 
Table 1. Selection of fit parameters for measured activation spectra in the deposition mode for a tropopause relevant temperature range from $-30^{\circ} \mathrm{C}$ to $-55^{\circ} \mathrm{C}$. Fit parameters for montmorillonite and kaolinite particles with diameters of 200,400 and $800 \mathrm{~nm}$ are given. The parameters are the free fit variable $\alpha$ and $\beta, S_{0}(\%)$ indicating the measured ice saturation causing $1 \%$ activated fraction and the maximum measured supersaturation $S_{\max }(\%)$.

\begin{tabular}{|c|c|c|c|c|c|c|}
\hline Dust species & Diameter (nm) & Temperature $\left({ }^{\circ} \mathrm{C}\right)$ & $\alpha$ & $\beta$ & $S_{0}(\%)$ & $S_{\max }(\%)$ \\
\hline \multirow[t]{17}{*}{ Montmorillonite } & 200 & -35 & 137 & 0.110 & 115.3 & 126.3 \\
\hline & 200 & -40 & 86 & 0.342 & 110.1 & 114.9 \\
\hline & 200 & -45 & 96 & 0.592 & 108.7 & 110.8 \\
\hline & 200 & -50 & 75 & 0.398 & 112.1 & 118.0 \\
\hline & 200 & -55 & 60 & 0.212 & 116.6 & 126.7 \\
\hline & 400 & -30 & 117 & 0.191 & 120.4 & 128.7 \\
\hline & 400 & -35 & 43 & 0.178 & 109.0 & 117.4 \\
\hline & 400 & -40 & 114 & 0.794 & 107.6 & 108.4 \\
\hline & 400 & -45 & 73 & 0.368 & 108.5 & 114.3 \\
\hline & 400 & -50 & 82 & 0.341 & 111.7 & 116.7 \\
\hline & 400 & -55 & 50 & 0.169 & 111.8 & 118.1 \\
\hline & 800 & -30 & 106 & 0.488 & 110.8 & 111.4 \\
\hline & 800 & -35 & 27 & 0.557 & 106.2 & 109.7 \\
\hline & 800 & -40 & 38 & 0.807 & 106.7 & 109.4 \\
\hline & 800 & -45 & 40 & 0.776 & 108.2 & 110.8 \\
\hline & 800 & -50 & 35 & 0.381 & 111.4 & 117.8 \\
\hline & 800 & -55 & 104 & 0.259 & 117.9 & 119.8 \\
\hline \multirow[t]{17}{*}{ Kaolinite } & 200 & -35 & 106 & 0.182 & 126.2 & 135.8 \\
\hline & 200 & -40 & 94 & 0.339 & 115.0 & 119.4 \\
\hline & 200 & -45 & 55 & 0.212 & 111.0 & 122.2 \\
\hline & 200 & -50 & 44 & 0.190 & 110.9 & 124.3 \\
\hline & 200 & -55 & 41 & 0.197 & 115.0 & 128.7 \\
\hline & 400 & -30 & 111 & 0.150 & 129.6 & 129.9 \\
\hline & 400 & -35 & 71 & 0.327 & 111.5 & 115.8 \\
\hline & 400 & -40 & 105 & 0.296 & 108.5 & 114.4 \\
\hline & 400 & -45 & 43 & 0.328 & 108.6 & 114.8 \\
\hline & 400 & -50 & 58 & 0.323 & 110.5 & 117.0 \\
\hline & 400 & -55 & 94 & 0.363 & 115.1 & 121.6 \\
\hline & 800 & -30 & 87 & 0.144 & 128.8 & 131.0 \\
\hline & 800 & -35 & 100 & 0.253 & 109.4 & 114.1 \\
\hline & 800 & -40 & 32 & 0.293 & 107.2 & 114.1 \\
\hline & 800 & -45 & 36 & 0.424 & 108.0 & 114.1 \\
\hline & 800 & -50 & 74 & 0.444 & 110.1 & 116.7 \\
\hline & 800 & -55 & 113 & 0.374 & 114.8 & 119.3 \\
\hline
\end{tabular}

$\mathrm{RH}_{i} \mathrm{~s}$. Differences in the absolute onset $\mathrm{RH}_{i}$ up to $30 \%$ have been observed for the used particle sizes. The size dependency is less pronounced at $-50^{\circ} \mathrm{C}$ and below i.e. the lines of the activation spectra lie close together. This indicates the presence of efficient active sites on the surfaces of all tested particle sizes that are able to support ice embryo formation under these conditions. It can be concluded that the probability for at least one efficient active site to be present on a IN surface depends more strongly on the particle size at higher temperature than at lower temperatures.
Assuming that all particles of one dust species have identical surface properties and the ability to nucleate ice per surface area is similar, surface normalized activation spectra should become uniform and overlay. This hypothesis has been tested by normalizing the activated fraction for all particle diameters to the $200 \mathrm{~nm}$ particle surface. Presuming that the particles are spherical, the activated fraction of the $100 \mathrm{~nm}$ particles would have to be multiplied by 4 , the activated fraction of the $400 \mathrm{~nm}$ particle divided by 4 and the one of $800 \mathrm{~nm}$ particles by 16 respectively. The simplified assumption of spherical shaped particles represents the maximum increase in particle surface with increasing 

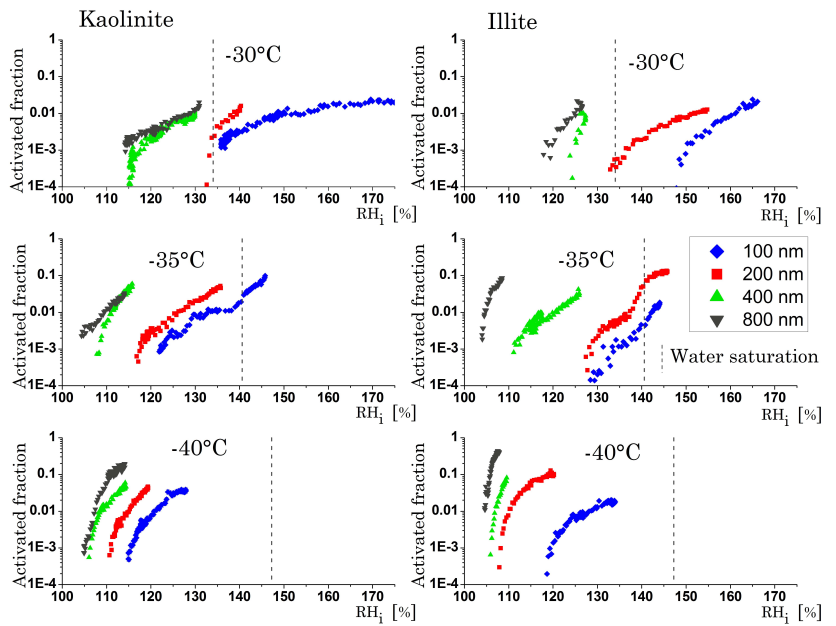

Fig. 6. Activation spectra of kaolinite and illite (activated fraction vs. $\mathrm{RH}_{i}$ ) for temperatures from $-30^{\circ} \mathrm{C}$ to $-40^{\circ} \mathrm{C}$. The particle diameter is indicated in the figure and water saturation has been marked as a vertical line. The combined uncertainty associated with the activated fraction is $14 \%$.

diameter and is commonly applied in the theory of ice nucleation (Pruppacher and Klett, 1997). Multiple charged particles were considered in these calculations, in the way that the average diameter of all particles with the same electrostatic mobility which exited the DMA was used for the normalization. Depending on the size distribution of the dust species, the average particle size differs $6-11 \%$ for $100 \mathrm{~nm}, 14-23 \%$ for $200 \mathrm{~nm}, 3-8 \%$ for $400 \mathrm{~nm}$ and $0-2 \%$ for $800 \mathrm{~nm}$ particles. The surface normalized activation spectra for illite are shown in Fig. 8. Similar results have been obtained for kaolinite, montmorillonite and ATD (cf. supplement http://www.atmos-chem-phys.net/ 9/6705/2009/acp-9-6705-2009-supplement.pdf).

The comparison of the normalized activation spectra indicates a substantial influence of the surface area. Especially for temperatures at $-40^{\circ} \mathrm{C}$ and below where the normalized activation spectra start to fall on top of each other for particles larger or equal $200 \mathrm{~nm}$, the activated fraction is dominated by the surface area of the selected particles. The effect of the total surface area on the onset relative humidity for deposition nucleation has been investigated by Kanji et al. (2008). They found a major influence of the surface area for montmorillonite, kaolinite and ATD at $-40^{\circ} \mathrm{C}$. The surface normalized comparison of our measurements confirm this observation for temperatures between $-40^{\circ} \mathrm{C}$ and $-45^{\circ} \mathrm{C}$.

In contrast to montmorillonite and ATD where the surface normalized activation spectra of all particle sizes coincide in the regime of deposition nucleation, a difference in the ice nucleation efficiency of kaolinite and illite occurs for $100 \mathrm{~nm}$ particles. The smallest size is clearly separated (see Fig. 8). This indicates a size limit for efficient deposition nucleation

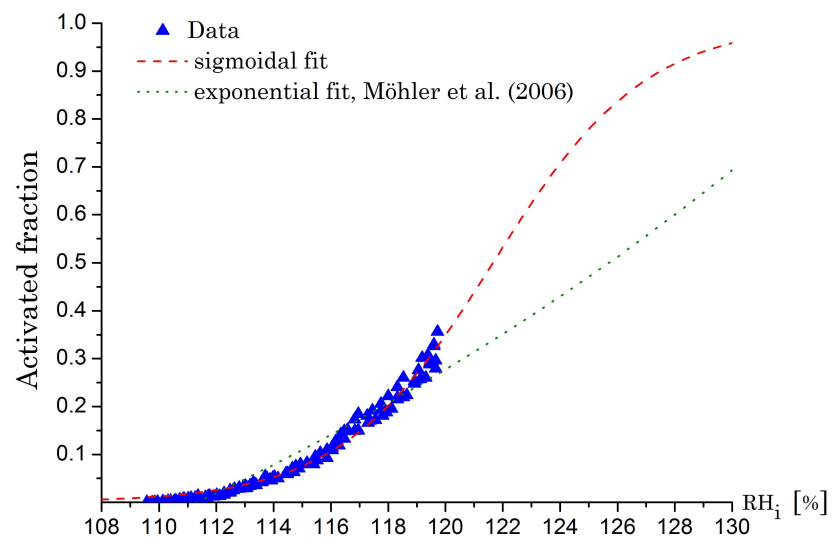

Fig. 7. Measured activation spectra at $-55^{\circ} \mathrm{C}$ for $400 \mathrm{~nm}$ illite particles are shown as blue triangles. The least square fit of a sigmoidal shaped curve according to Eq. (2) is depicted as dashed line. The least square fit of an exponential parameterisation according to Möhler et al. (2006) is shown as dotted line.

around $100 \mathrm{~nm}$ for these dust species in agreement with the results obtained by Marcolli et al. (2007) who analysed ATD in the immersion mode. They also found that particles have to have a diameter of at least $100 \mathrm{~nm}$ to carry one active site on average for temperatures below $-20^{\circ} \mathrm{C}$.

Ice nucleation efficiencies of the different mineral dust species were compared by looking at the activated fraction as a function of $\mathrm{RH}_{i}$, shown in Fig. 9, where activation spectra of all four mineral dusts are plotted together and in terms of the contact angle $\theta$ between the critical ice embryo and the dust particle, visualized in Fig. 10. Contact angles, frequently referred to as wettability (Pruppacher and Klett, 1997) were calculated folowing Chen et al. (2008) without considering curvature adjustment which are negligible for aerosol sizes $\geq 0.1 \mu \mathrm{m}$. The nucleation rate that is needed for the calculation of the contact angle is the one used for $1 \%$ activation. For temperatures below circa $-35^{\circ} \mathrm{C}$ where deposition nucleation prevails, contact angles of different species appear to be similar and do not depend on temperature. The calculated contact angles are slightly smaller, but confirm the order of magnitude reported by Eastwood et al. (2008). Efficient IN have small contact angles (Pruppacher and Klett, 1997) and exhibit a steep increase in the activated fraction at low $\mathrm{RH}_{i}$. The comparison of the nucleation spectra in Fig. 9 and contact angles in Fig. 10 between the different dust species shows no simple pattern which would allow to isolate one mineral dust type as the most efficient IN in the deposition mode. Differences to the results of other studies e.g. by Salam et al. (2006) who found a superior nucleation efficiency of montmorillonite compared to kaolinite, may be due to the size selection of the particles or the use of a different threshold for activation. In summary, no outstanding particle property has been identified as being 

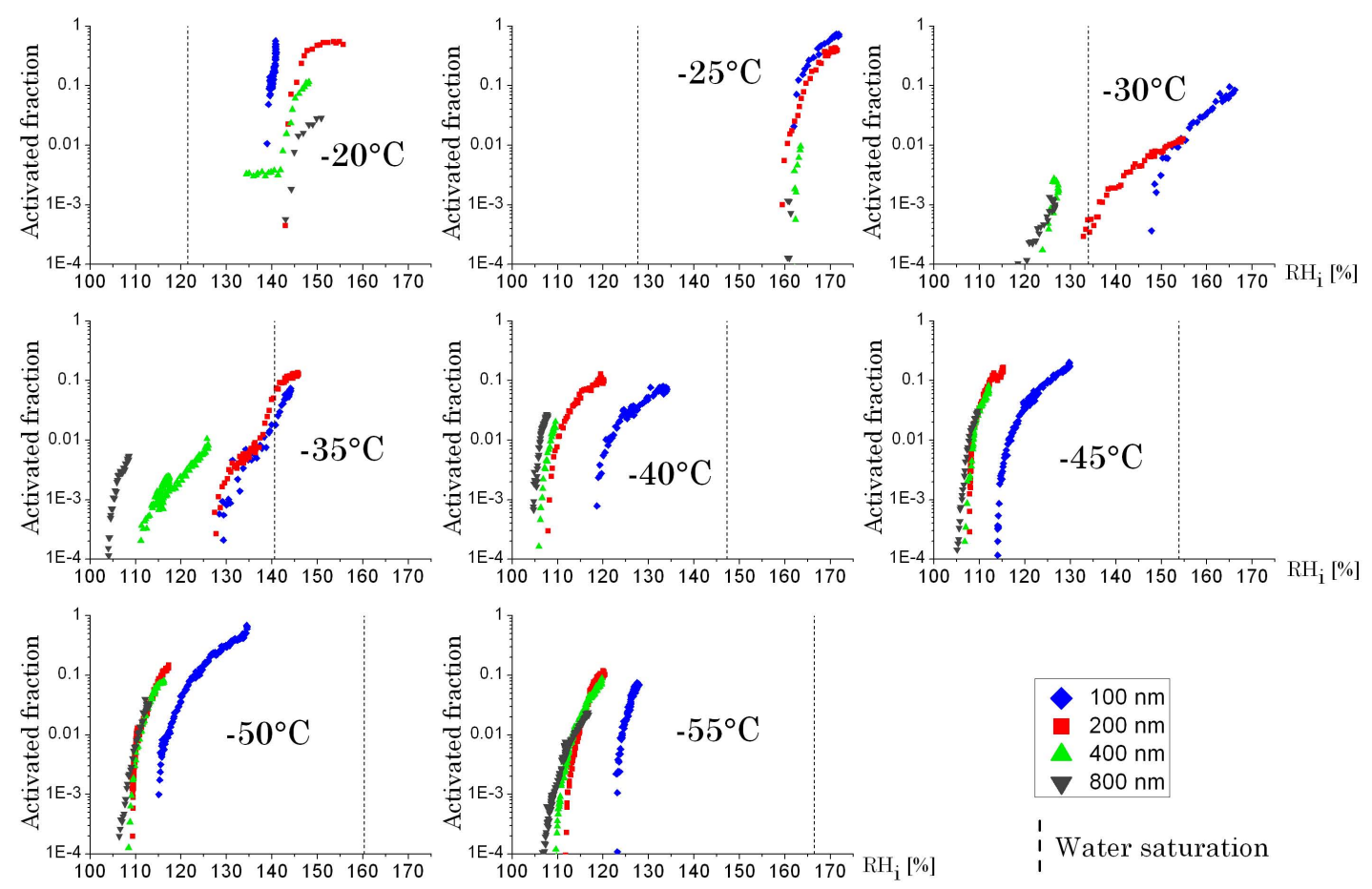

Fig. 8. Surface normalized activation spectra (activated fraction vs. $\mathrm{RH}_{i}$ ) of illite. The activated fraction of the different particle sizes has been normalized to an equivalent surface of a $200 \mathrm{~nm}$ particle. The combined uncertainty associated with the activated fraction is $14 \%$.

the dominant one for deposition nucleation. Possible properties are amphoteric behavior (ability to undergo hydrogen bonds), lattice structure, hydrophilicity, hygroscopicity or the quality of active sites present on the particle surface (Rogers and Yau, 1989; Hu and Michaelides, 2007; Seisel et al., 2005; Kanji et al., 2008; Chen et al., 2008; Pruppacher and Klett, 1997). Probably it is a combination of all these attributes that contributes to the IN efficiency of a dust species.

The temperature range in which deposition is the only active nucleation mechanism depends on size and dust species (see Fig. 6). Larger particle sizes $(400 \mathrm{~nm}$ and $800 \mathrm{~nm}$ ) nucleate ice distinctly in deposition mode below water saturation at temperatures up to $-30^{\circ} \mathrm{C}$. Above this temperature, ice nucleation only occurs above water saturation. The separation of condensation freezing and deposition nucleation above water saturation is not possible with the present experimental setup. But the onset of condensation freezing should be clearly visible in the activation spectra. Condensation freezing occurs only above water saturation. As both condensation freezing and deposition nucleation contribute to the activation spectra, the onset of condensation freezing can be detected as a sharp increase in the slope of the activation spectra at water saturation. Examples of activation spectra crossing the water saturation line are shown in Fig. 6. In some cases (e.g. ATD particles with an electrical mobility diameter of 100 and $200 \mathrm{~nm}$ ) the transition over the water saturation line does not involve a distinctive change in the activated fraction. A possible interpretation is either an equivalent compensation of the reduced deposition nucleation by the onset of condensation freezing or that deposition nucleation is the prevailing mechanism to form ice even above water saturation. Fig. 10 shows a change in the contact angle at temperatures around $-35^{\circ} \mathrm{C}$, the same temperature where condensation nucleation starts to be active. Thus, a change in $\theta$ probably indicates a change in the nucleation mechanism (cf. Fig. 5). The only exception occurs for ATD, where a constant $\theta$ suggests that even at temperatures above $-30^{\circ} \mathrm{C}$ deposition nucleation prevails.

The direct comparison of our data to results of previous investigations is not trivial, as particle preparation, particle size or experimental methods differ.

\section{Conclusions}

In this paper, experiments were performed with the recently constructed continuous flow diffusion chamber ZINC. The results describe the ice nucleation behaviour of four different mineral dust aerosols under atmospheric conditions. Montmorillonite, kaolinite, illite and ATD have been observed to act efficiently as IN. The larger the particle diameter of a dust aerosol, the more efficient the ice formation in deposition 


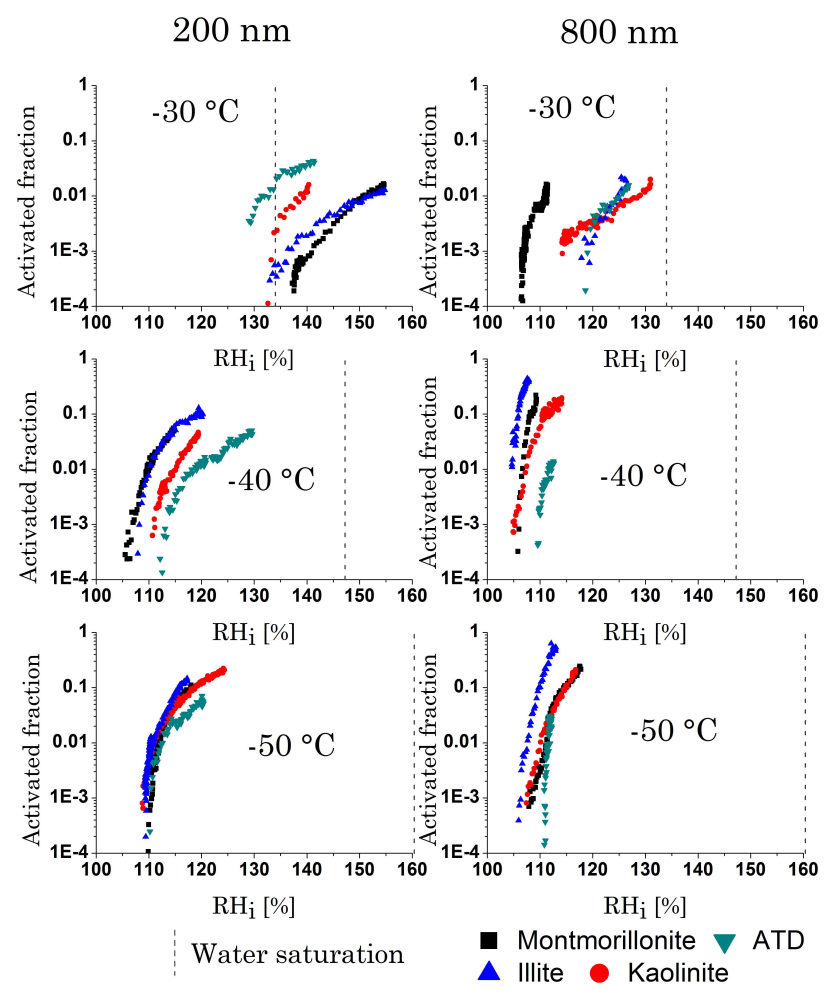

Fig. 9. Comparison of the activation spectra of montmorillonite, kaolinite, illite and ATD for $200 \mathrm{~nm}$ and $800 \mathrm{~nm}$ particles at $-30^{\circ} \mathrm{C}$, $-40^{\circ} \mathrm{C}$ and $-50^{\circ} \mathrm{C}$. Water saturation is indicated as vertical line. The combined uncertainty associated with the activated fraction is $14 \%$.

mode for the temperature range from $-30^{\circ} \mathrm{C}$ to $-55^{\circ} \mathrm{C}$. The size effect is less pronounced at lower temperatures.

A sigmoidal shaped fitcurve for use in cloud and climate models is proposed for the parameterisation of the ice activated fraction of dust particles for conditions below water saturation in the temperature range between $-30^{\circ} \mathrm{C}$ to $-55^{\circ} \mathrm{C}$.

It is likely that the ice nucleation ability of a dust type depends on the surface properties of the dust particles. The comparison of the nucleation efficiency among the four dust species used in this study shows no superior nucleation ability of one mineral dust. Therefore no specific dust property can be declared as the most important for ice nucleation. The further data analysis according to the method described by Chen et al. (2008) indicates contact angles similar or at least in the same order of magnitude for all dust species at temperatures below $-40^{\circ} \mathrm{C}$.

A transition from deposition nucleation to condensation freezing has been observed for some dust particles when water saturation was reached. Improved measuring instruments and the ability to distinguish water droplets from ice particles with depolarisation or holographic measurements could

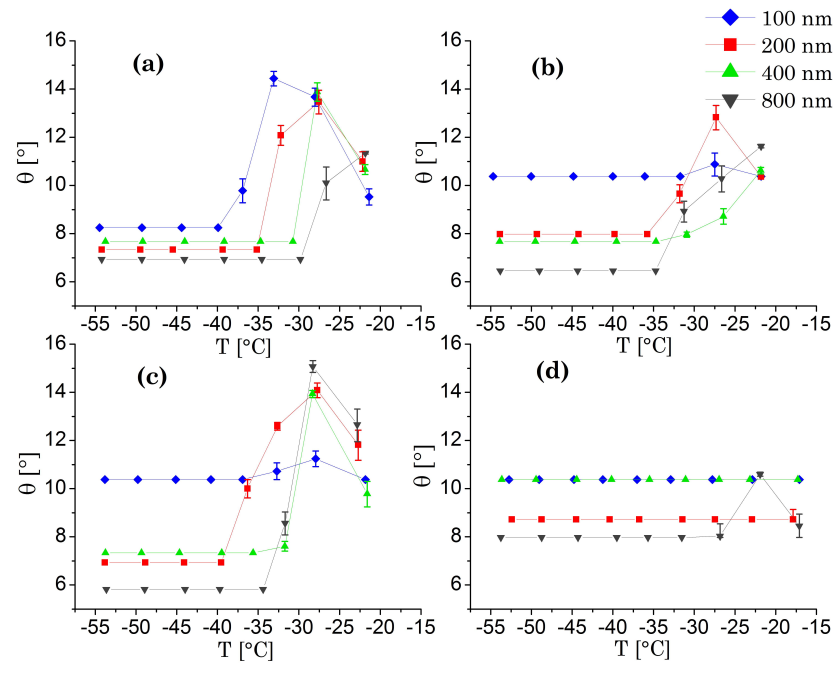

Fig. 10. Calculated contact angles for deposition nucleation $(\theta)$ for (a) montmorillonite, (b) kaolinite, (c) illite and (d) ATD. As the calculated contact angles are not sensitive to small changes in $\mathrm{RH}_{i}$, the corresponding error of the contact angle is mostly small i.e. the error bar is covered by the data symbol.

be used in future studies to investigate the transition between one nucleation mode to another in more depth. The microphysical properties of dust particles for instance, the area density and nature of active sites and the dependency on the $\mathrm{RH}_{i}$, enabling them to initiate ice embryo formation must be addressed in future studies to improve the understanding of ice formation on IN.

Acknowledgements. We would like to thank E. Barthazy from ETH Zurich Electron Microscopy (EMEZ) for making the SEM images. We also thank Arginotec for providing us the illite samples. We acknowledge financial support from the EU project EUCAARI (European Integrated project on Aerosol Cloud Climate and Air Quality interactions) No. 036833-2.

Edited by: Prof. A. Wiedensohler

\section{References}

Archuleta, C., DeMott, P., and Kreidenweis, S.: Ice nucleation by surrogates for atmospheric mineral dust and mineral dust/sulfate particles at cirrus temperatures, Atmos. Chem. Phys., 5, 26172634, 2005, http://www.atmos-chem-phys.net/5/2617/2005/.

Berezinski, N., Stepanov, G., and Khorguani, V.: Atmospheric Aerosols and Nucleation, chap. Ice-forming activity of atmospheric aerosol particles of different sizes, 709-712, Springer Berlin/Heidelberg, 1988.

Chen, J.-P., Hazra, A., and Levin, Z.: Parameterizing ice nucleation rates using contact angle and activation energy derived from laboratory data, Atmos. Chem. Phys., 8, 7431-7449, 2008, http://www.atmos-chem-phys.net/8/7431/2008/. 
Claquin, T., Schulz, M., and Balkanski, Y.: Modeling the mineralogy of atmospheric dust sources, J. Geophys. Res., 104, 22243 22256, 1999.

DeMott, P., Czico, D., Prenni, A., Murphy, D., Kreidenweis, S., Thomson, D., Borys, R., and Rogers, D.: Measurements of the concentration and composition of nuclei for cirrus formation, Proc. Natl. Acad. Sci. USA, 100(25), 14655-14660, 2003a.

DeMott, P., Sassen, K., Poellot, M., Baumgardner, D., Rogers, D., Brooks, S., Prenni, A., and Kreidenweis, S.: African dust aerosols as atmospheric ice nuclei, Geophys. Res. Lett., 30(14), 1732, doi:10.1029/2003GL017410, 2003 b.

Eastwood, M. L., Cremel, S., Gehrke, C., Giard, E., and Bertram, A. K.: Ice nucleation on mineral dust particles: Onset conditions, nucleation rates and contact angles, J. Geophys. Res., 113, D22203, doi:10.1029/2008JD010639, 2008.

Heymsfield, A. E. A.: The Ice in Clouds Experiment - Reserch Plan -, Scientific Overview Document, www.mmm.ucar.edu/events/ ice05/images/ICE-SOD-050902.pdf, 2005.

$\mathrm{Hu}, \mathrm{X}$. and Michaelides, A.: Ice formation on kaolinite: Lattice match or amphoterism?, Surface Science, 601, 5378-5381, 2007.

Kanji, Z., Florea, O., and Abbatt, J.: Ice formation via deposition nucleation on mineral dust and organics: dependence of onset relative humidity on total particulate surface area, Environ. Res. Lett., 3, 025004, doi:10.1088/1748-9326/3/2/025004, 2008.

Kim, S., Woo, K., Liu, B., and Zachariah, M.: Method of measuring charge distribution of nanosized aerosols, J. Coll. Interface Sci., 282, 46-57, 2005.

Knopf, D. and Koop, T.: Heterogeneous nucleation of ice on surrogates of mineral dust, J. Geophys. Res., 111, D12201, doi:10.1029/2005JD006894, 2006.

Lau, K. and $\mathrm{Wu}, \mathrm{H}$.: Warm rain processes over tropical oceans and climate implications, Geophys. Res. Lett., 30, 2290-2294, 2003.

Li, X., Maring, H., Savoie, D., Voss, K., and Prospero, J.: Dominance of mineral dust in aerosol light-scattering in the North Atlantic trade winds, Nature, 380, 416-419, 1996.

Marcolli, C., Gedamke, S., and Zobrist, B.: Efficiency of immersion mode ice nucleation on surrogates of mineral dust, Atmos. Chem. Phys., 7, 5081-5091, 2007, http://www.atmos-chem-phys.net/7/5081/2007/.

Möhler, O., Field, P., Connolly, P., Benz, S., Saathoff, M., Wagner, R., Cotton, R., Krämer, M., Mangold, A., and Heymsfield, A.: Efficiency of the deposition mode ice nucleation on mineral dust particles, Atmos. Chem. Phys., 6, 3007-3021, 2006, http://www.atmos-chem-phys.net/6/3007/2006/.

Möhler, O., Linke, C., Saathoff, M., Schnaiter, M., Wagner, R., Mangold, A., Krämer, M., and Schurath, U.: Ice nucleation on flame soot aerosol of different organic carbon content, Meteorol. Z., 14(4), 477484, 2005.

Prospero, J.: Long-range transport of mineral dust in the global atmosphere: Impact of African dust on the environment of the southeastern United States, Proc. Natl. Acad. Sci. USA, 96(7), 3396-3403, 1999.
Pruppacher, H. and Klett, J.: Microphysics of clouds and precipitation, Springer Netherlands, 1997.

Roberts, P. and Hallett, J.: A laboratory study of ice nucleating properties of some mineral particles, Q. J. Roy. Meteorol. Soc. 94, 25-34, 1968.

Rogers, R. and Yau, M.: A short course in Cloud Physics, Pergamon, Tarrytown, NY, 1989.

Salam, A., Lohmann, U., Drenna, B., Leisins, G., Klages, P., Rogers, D., Irani, R., MacGillivray, A., and Coffin, M.: Ice Nucleation Studies of Mineral Dust Particles with a New Continuous Diffusion Chamber, Aerosol Sci.Technol., 40, 134-143, 2006.

Seisel, S., Pashkova, A., Lian, Y., and Zellner, R.: Water uptake on mineral dust and soot: A fundamental view of the hydrophilicity of atmospheric particles?, Faraday Discussion, 130, 1-15, 2005.

Stetzer, O., Baschek, B., Lüönd, F., and Lohmann, U.: The Zurich Ice Nucleation Chamber (ZINC) - A new instrument to investigate atmospheric ice formation, Aerosol Sci. Technol., 42, 6474, 2008.

Szyrmer, W. and Zawadzki, I.: Biogenic and Anthropogenic Sources of Ice-Forming Nuclei: A Review, B. Am. Meteorol. Soc., 78(2), 209-212, 1997.

Tegen, I., Werner, M., Harrison, P., and Kohfeld, K.: Relative importance of climate and land use in determining present and future global soil dust emission, Geophys. Res. Lett., 31, L05105, doi:10.1029/2003GL019216, 2004.

Vali, G.: Ice Nucleation - Theorie, Presentation at the NCAR/ASP 1999 Summer Colloquium, http://tierra.rediris.es/ megacryometeors/icenucleation.pdf, 1999.

Wallace, J. M. and Hobbs, P.: Atmospheric Science: an introductory survey, Elsevier, 2006.

Warren, S. and Eastman, R.: A Survey of Changes in Cloud Cover and Cloud Types over Land from Surface Observations, 1971-96, Am. Meteor. Soc., 20, 717-738, 2007.

Winkler, P., Steiner, G., Vrtala, A., Vehkamki, H., Noppel, M., Lehtinen, K., Reischl, G., Wagner, P., and Kulmala, M.: Heterogeneous Nucleation Experiments Bridging the Scale from Molecular Ion Clusters to Nanoparticles, Science, 319, 1374 1377, 2008.

Zimmermann, F., Weinbruch, S., Schuetz, L., Hofmann, H., Ebert, M., Kandler, K., and Worringen, A.: Ice nucleation properties of the most abundant mineral dust phases, J. Geophys. Res., 113, D23204, doi:10.1029/2008JD01655, 2008.

Zhang, Y., Macke, A., and Albers, F.: Effect of crystal size spectrum and crystal shape on stratiform cirrus radiative forcing, Atmos. Res., 52, 59-75, 1999. 